\title{
Evaluation of the effects of concentration, duration and temperature of incubation with Beta-Propiolactone on inactivation of cell-derived rabies virus
}

\author{
Eftekhari $Z^{1 *}$, Mehrbod $\mathbf{P}^{2}$, Vaez $\mathbf{J}^{1}$, Hosseini SM${ }^{1}$, Jodairi Eslami $\mathbf{S}^{1}$ \\ ${ }^{1}$ Research and Production Complex, Pasteur Institute of Iran. Alborz, Iran. \\ ${ }^{2}$ Influenza and Other Respiratory Virus Dept, Pasteur Institute of Iran, Tehran, Iran.
}

\begin{abstract}
Introduction: During the production process of vaccines against viral diseases, virus inactivation plays a crucial role. $\beta$-Propiolactone (BPL) is a compound that is frequently used for inactivation of viruses and production of the vaccines against viral diseases such as rabies. In this study, the effects of concentration of BPL as well as the duration and temperature of incubation with BPL on the infectivity of the rabies virus was investigated. Methods: Fixed rabies (Pasteur Virus) PV strain grown on BHK21C13 cell was treated with 1:3000, 1:4000 and 1:5000 final concentrations of BPL at $4^{\circ} \mathrm{C}, 21^{\circ} \mathrm{C}$ and $37^{\circ} \mathrm{C}$ and their effects were evaluated after $24,48,72 \mathrm{~h}$ and 5 days. Each sample was titrated after various intervals and tested for the viral infectivity in BSR cells. The BSR cells were infected by triple serial dilutions of the rabies virus PV strain, and then infectivity was detected by the fluorescent technique. Results: Entire loss of infectivity of the virus treated at $4^{\circ} \mathrm{C}$ with 1:3000 and 1:4000 of BPL was evident at the end of the 24 and $48 \mathrm{~h}$ incubation periods, respectively. Moreover, the loss of infectivity of the virus treated with all tested concentrations of BPL was evident at the end of the $72 \mathrm{~h}$ at $21^{\circ} \mathrm{C}$ and $4{ }^{\circ} \mathrm{C}$. Conclusion: These findings suggest that aside from BPL concentration, temperature plays the most important role on BPL inactivation. The inactivation effect could be observed at the end of $72 \mathrm{~h}$ incubation period; however, the best economic condition for rabies virus inactivation was shown to be $1: 4000$ at $4{ }^{\circ} \mathrm{C}$ for $48 \mathrm{~h}$.
\end{abstract}

KEYWORDS: Rabies virus, $\beta$-Propiolactone, Inactivation.

\section{INTRODUCTION}

Rabies is caused by rod- or bullet-shaped neurotropic viruses of the genus Lyssavirus belonging to the family Rhabdoviridae. This family consists of viruses enveloped with a negative-sense ssRNA genome [19]. Rabies is an acute viral disease of the central nervous system which is infectious to all mammals and causes inflammation of the brain. It is one of the oldest important viral diseases shared between animals and humans [10]. Since 1958 when rabies virus was first grown in hamster kidney cells, considerable progress has been made in the field of in-vitro cell culture and of techniques for adapting and replicating rabies virus in these cells. Such techniques have recently led to the development of a second generation of rabies vaccines. Among the second-generation vaccines for veterinary use, several types can be distinguished depending on whether they are live or inactivated, the strain of rabies virus used and

*Corresponding Author: Zohre Eftekhari, Research and Production Complex, Pasteur Institute of Iran, Alborz, Iran.

Email: Eftekharivet@gmail.com

Tel/Fax: (+98) 2636100937/ (+98) 2636102900 the characteristics of the cell substrate chosen for the viral replication $[10,8]$.

The main virus strain used for the production of rabies vaccines for veterinary use is Pasteur Virus (PV) strain. Two types of cell substrates are generally used in the production of rabies vaccines for veterinary use which include primary cells from the organs of adult or newborn animals, embryos, diploid cells or continuous cell lines. These cell lines are mainly derived from hamster kidney cells, such as BHK and Nil-2 lines [17]. Veterinary rabies vaccine which is routinely produced, contains tissue culture-adapted rabies PV strain propagated on BHK-21 cells. There are two types of cell-culture rabies vaccines for veterinary use that include live attenuated vaccines and inactivated [10]. The inactivated cell culture vaccines have been shown to be safe and highly effective for veterinary use. Such vaccines have been approved for the mass immunization of domestic carnivores and cattle [7].

Various methods can be used for inactivating the rabies virus, such as treatment with $\beta$-propiolactone (BPL), acetylethyenemine or other imines or ultraviolet irradiation. 
However, phenol and formaldehyde are no longer recommended, since they may reduce the immunogenicity of the virus and may cause release of toxic or irritant residues. The most commonly used inactivating agent is BPL, used generally at a concentration of 1:4000 and in a medium with an appropriate $\mathrm{pH}[2,4]$. BPL kills both bacteria and viruses with no effect on the antigenicily of the rabies virus [3]. Several methods that combine the application of temperature and BPL are often applied to ensure the complete inactivation of the virus and total hydrolysis of the inactivating agent [10].

Rabies causes about 24,000 to 60,000 deaths worldwide, annually. More than $95 \%$ of human deaths caused by rabies occur in Asia and Africa. Animal control and vaccination programs have decreased the risk of rabies from infected animals in a number of regions of the world. Immunization of people at high risk such as veterinarians and rabies laboratory experts is recommended before potential exposures [19]. To obtain high degree of potency, however, it is essential to select a highly productive cell culture system and to apply a production protocol that not only ensures high yields but also conserves the antigenicity of the virus during many steps of manufacturing [10]. The aim of this study was to evaluate the effects of temperature, time of exposure and concentrations of BPL on the infectivity of the rabies virus, in order to achieve the ideal conditions for inactivation of the virus, harvested from the cell cultures.

\section{MATERIALS and METHODS}

\section{Mice}

Female NMRI mice, 3-4 weeks old (12-14 g) were purchased from the animal facility of Production and Research Complex of Pasteur Institute of Iran in Karaj. All experimental procedures involving animals were approved by the Ethics Committee of Biomedical Research (IR.PII.REC.1394.30).

\section{BHK21C13 cell culture}

The culture medium contained DMEM (Hi-Media, India), supplemented with 7\% fetal bovine serum (Gibco $\mathrm{TM}$ ) and gentamycin $(0.01 \%)$. BHK21C13 cells were transferred to cell culture flasks under aseptic conditions $(1.5 \times 105$ cells $/ \mathrm{ml})$. The flasks were incubated at $37^{\circ} \mathrm{C}$ for $72 \mathrm{~h}$ and the cells were then stained with trypan blue $0.4 \%$ and the number of live and dead cells were recorded. The cells $(2 \times 105$ cells $/ \mathrm{ml})$ were cultured in $700 \mathrm{ml}$ culture medium as above.

\section{PVS inoculation and culture in bioreactor}

Before adding the virus, the contents of flasks were collected and centrifuged at $700 \mathrm{x} \mathrm{g}$ for $10 \mathrm{~min}$. The obtained packed deposits were then re-suspended in DMEM containing gentamicin $(0.01 \%)$ and BSA $(0.3 \%)$. The effects of multiplicity of infection (MOI) and type of medium used for the virus multiplication in spinner-flasks showed that the highest virus titter at a MOI of 0.3 was achieved in M199 medium supplemented with $0.2 \%$ of BSA and was equal to $8.2 \times 107$ Fluorescent Focus Units (FFU/ml). The virus was added at a MOI of 0.3 and the contents $(\sim 71)$ were transferred into the bioreactor for 5 days so that the cell count was about 2 million cells $/ \mathrm{ml}$

\section{Inactivation of the virus using BPL}

After harvesting, the virus was divided into different segments for evaluation of different concentrations and temperatures of the inactivating agent. BPL (Sigma Chemicals) which is generally used at concentration of 1:4000 was employed to inactivate one segment for $2 \mathrm{~h}$ on magnetic stirrer at $4^{\circ} \mathrm{C}$. This is a routine procedure in veterinary rabies vaccine production department of Pasteur Institute of Iran and was used here as a comparison to other results achieved in present study. Other segments containing fixed rabies virus PV strain grown in BHK21C13 cells were treated with 1:3000, 1:4000 and 1:5000 final concentrations of BPL while each dilution was incubated separately at $4^{\circ} \mathrm{C}, 21^{\circ} \mathrm{C}$ and $37^{\circ} \mathrm{C}$ and was evaluated after 24 , $48,72 \mathrm{~h}$ and 5 days.

\section{In-vitro and in-vivo inactivity tests}

Each sample was checked for the viral infectivity by both mice inoculation and titration in BSR cells using the fluorescent focus method in 48-well tissue culture plates. Briefly, BSR cells were developed as monolayers and tenfold dilutions of the virus by DMEM containing gentamicin $(0.01 \%)$ and BSA $(0.3 \%)$ were added to each well $(100 \mu \mathrm{l} /$ well), incubated for $1 \mathrm{~h}$ at $37^{\circ} \mathrm{C}$ after which fresh medium was added. The plates were then incubated for $72 \mathrm{~h}$ in a $\mathrm{CO} 2$ incubator, followed by staining with anti-rabies nucleocapsid conjugate (Bio-Rad \#3572114) and observation using an immunofluorescence (IF) technique. The fluorescent focus units (FFU/ml) titer was calculated after staining the BSR cells in the tissue culture plate with FITC rabies conjugate (anti-rabies nucleocapsid conjugate, Bio-Rad \# 3572114) using standard procedures.

For more evaluations, one sample of each dilution was selected for in-vivo test. Ten NMRI mice were inoculated intracerebrally for each inactivated samples. Totally, 100 mice were selected in ten groups (10 mice/group) for evaluation of inactivated samples with different concentration at different temperatures. The vital signs of the mice were checked before the experiment and adaptation period, for two days and after adaptation period, the mice were anesthetized by diethyl ether. Intra-cerebral challenge was carried out by $0.03 \mathrm{ml}$ each sample injected and the animals were observed daily for 14 days. A mouse LD50 titer of each aliquot was calculated by the Reed and Muench method after 14-day observation of the inoculated mice as described previously [14].

\section{RESULTS}

Based on the in-vivo evaluation, for all inactivated samples, no death was reported in inoculated mice after 14 days which proved that all samples were inactivated by BPL. Also no infection (fluorescent focuses) was detected by immune fluorescence cell culture method. Complete loss of infectivity of the virus treated with 1:3000 and 1:4000 of BPL was evident at the end of the $24 \mathrm{~h}$ and $48 \mathrm{~h}$ at $4^{\circ} \mathrm{C}$. Moreover, the loss of infectivity of the virus treated with 1:3000, 1:4000 and 1:5000 final concentrations of BPL was evident at the end of the $72 \mathrm{~h}$ at $21^{\circ} \mathrm{C}$ and $4{ }^{\circ} \mathrm{C}$ incubation temperatures. Entire loss of infectivity of the virus treated with 1:3000, 1:4000 of BPL was evident at the end of the $48 \mathrm{~h}$ at $4{ }^{\circ} \mathrm{C}$ and $21^{\circ} \mathrm{C}$ (Fig. 1 and Fig. 2). As seen in Fig. 1, the fluorescent foci (i.e. green foci) was observed after $24 \mathrm{~h}$, using an immune-fluorescence (IF) microscope which confirmed the presence of active viruses. However, as shown in Fig. 2, complete loss of infectivity of the virus treated with 1:3000 and 1:4000 of BPL was evident at the end of the $48 \mathrm{~h}$ for which no fluorescent focus could be observed in the microscopic area. 

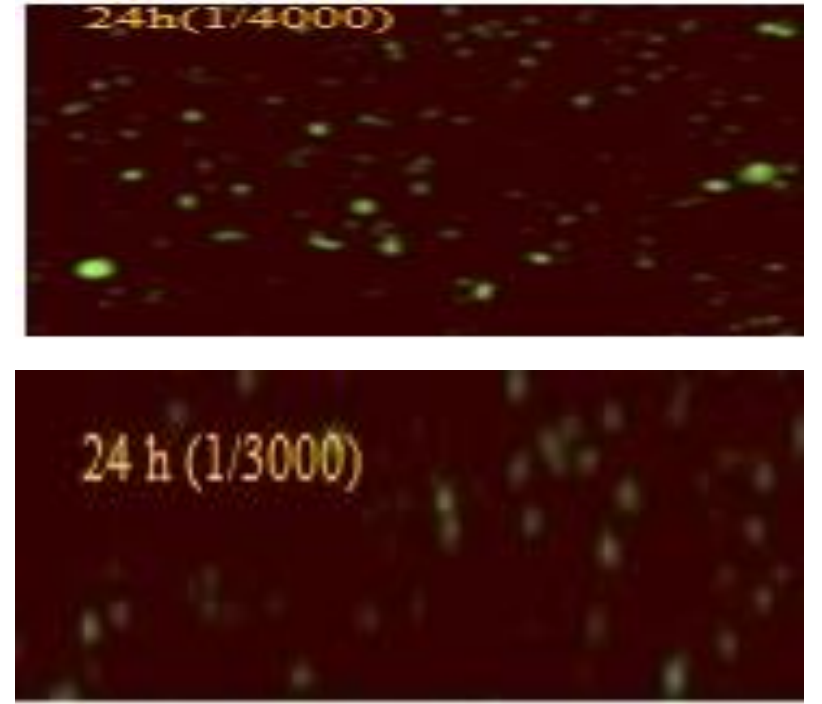

Fig. 1. The active virus observed by florescent microscope (Green areas) after $24 \mathrm{hr}$.)
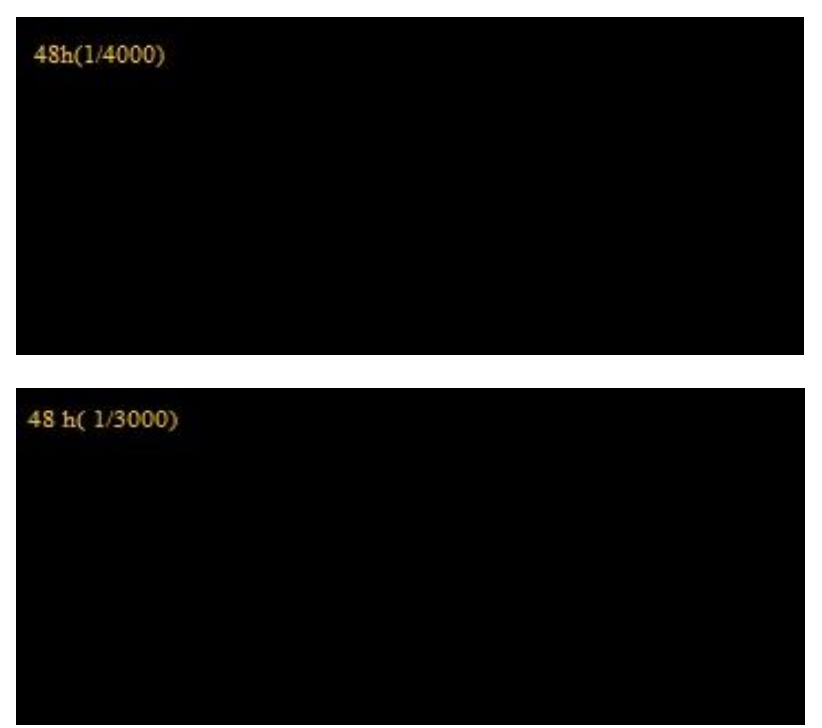

Fig. 2. Complete loss of infectivity of the virus treated with 1:3000 and 1:4000 of BPL was evident at the end of a $48 \mathrm{~h}$ incubation period.

When the lowest concentration of BPL (i.e. 1/5000) was used in present study, no significant reduction was observed at the end of $48 \mathrm{~h}$ in the infectivity titer (5× $105 \mathrm{FFU} / \mathrm{ml})$. At concentration of 1:3000, the infectivity titer (infection in cell culture) dropped from $6 \times 106 \mathrm{FFU} / \mathrm{ml}$ to $3 \times 102 \mathrm{FFU} / \mathrm{ml}$ at the end of the $24 \mathrm{~h}$ period which became zero at the end of $48 \mathrm{~h}$ period at $4^{\circ} \mathrm{C}$.

\section{DISCUSSION}

One of the most important ways to prevent rabies in humans and animals is vaccination of the farm animals and pets. To enhance the quality and potency of the vaccines and to reduce the production costs, the vaccine production procedures should be optimized. Validation of rabies virus inactivation process is a crucial part of quality assurance for the vaccine production companies where time is a critical factor in order to increase the inactivated harvest within the shortest period possible. Here, a total of 2 batches of harvest from a bioreactor containing fixed rabies virus PV strain grown on BHK21C13 cell were inactivated by different concentrations of BPL in different time periods and temperatures and the outcome were checked by FFU and in vivo tests.

BPL is a chemical agent that is widely used for the inactivation of viruses during preparation of vaccines against rabies and influenza. The mechanism of action of BPL is direct interaction with the nucleic acids. All reactions with BPL are rapid and constant where alkylation or acylation reactions with interacting nucleophiles which are frequently present in large biological macromolecules such as DNA and RNA are unalterable [6]. Viral inactivation is directly connected to the character of the virus, the composition of the solution during inactivation, the preliminary concentration of BPL and the ambient temperature [5].For vaccine productions, these parameters are commonly set at $4{ }^{\circ} \mathrm{C}$ for $18-24 \mathrm{~h}$ with BPL at a concentration of $0.1-0.25 \%$. However, these parameters can differ per pathogen [9] which for rabies virus, a concentration of not more than 1:3500 and up to $1: 5000(\mathrm{v} / \mathrm{v})$ of $\mathrm{BPL}$ at $2-8^{\circ} \mathrm{C}$ for $24 \mathrm{~h}$ are recommended [18].

Routinely, in Department of Veterinary Rabies Production of Pasteur Institute of Iran, the condition of BPL consumption is at concentration of $1: 4000(\mathrm{v} / \mathrm{v})$, incubated at $4^{\circ} \mathrm{C}$ for 5 days [10]. During the present study, different conditions of using BPL, such as different concentrations, incubation periods and temperatures were assayed to find an economic pattern of using this compound in rabies vaccine production lines. The results indicated that samples which were inactivated by BPL at 1:4000 concentrations for $48 \mathrm{~h}$ at refrigerator temperature (i.e $4^{\circ} \mathrm{C}$ ) gave the best output.

Due to the high cost of BPL and the importance of the time in vaccine production procedures, we tried to use high and low concentrations of BPL at different incubation times to achieve the best combination of incubation time, temperature and concentration for inactivation of rabies virus.

In a similar study done on influenza virus, the viruses were treated with $2 \mu \mathrm{M}$ BPL by which the virus lost about $50 \%$ of its cell infectivity compared to the native virus and in higher doses (10- and 125-fold), the virus lost its infectivity almost completely while treatment with $1 \mathrm{mM}$ BPL caused complete suppression of the infectivity [1,18].Moreover, it has been previously shown that other compounds, namely ascorbic acid and copper sulfate treatments at optimal concentration of 0.5 $\mathrm{mg} / \mathrm{ml}$ and $5 \mu \mathrm{g} / \mathrm{ml}$, respectively, could inactivate rabies virus after $72 \mathrm{~h}$ completely while the inactivated virus retained proper potency and antigenicity [11].

In the present study, viruses have been inactivated completely by a BPL in concentration of 1:3000 and 1:4000 when incubated for 24 and $48 \mathrm{~h}$ at $4^{\circ} \mathrm{C}$ which confirmed a previous study by Jagganathan et al in 2013 . The results also indicated that the inactivation effect is directly proportional to the concentration of BPL used in the process. On the other hand, BPL has the advantage that it does not require any neutralizing agent to stop its reaction and it is completely hydrolyzed in presence of the cell culture medium and cell debris [7]. By validation of the temperature for conservation of the virus activity beside the improvement of the production process and validation of IPQC (In-Process Quality Control), our data showed that temperature and concentration are the most important factors in BPL inactivation effect. At 1/4000 BPL concentration at $4{ }^{\circ} \mathrm{C}$, the inactivation effect could be achieved in a shorter incubation time $(48 \mathrm{~h}$; instead of a 5-day incubation) in the production lines. 


\section{ACKNOWLEDGEMENT}

The authors gratefully acknowledge the Research and Production Complex, Pasteur Institute of Iran in Karaj, for providing facilities to carry out this study.

\section{CONFLICT OF INTEREST}

The authors declare that they have no conflict of interest.

\section{REFERENCES}

1. Bonnafous P, Nicolai MC, Taveau JC, Chevalier M, Barriere F, Medina J, Le Bihan O, Adam O, Ronzon F, Lambert O (2014) Treatment of influenza virus with beta-propiolactone alters viral membrane fusion. Biochim Biophys Acta 1838 (1 Pt B):355-363. doi:10.1016/j.bbamem.2013.09.021. 2. Brown F (1995) Formaldehyde as an inactivant. Vaccine 13 (2):231.

3. Bruckner L, Cussler K, Halder M, Barrat J, Castle P, Duchow K, Gatewood DM, Gibert R, Groen J, Knapp B, Levis R, Milne C, Parker S, Stunkel K, Visser N, Volkers P, Ecvam (2003) Three Rs approaches in the quality control of inactivated rabies vaccines. The report and recommendations of ECVAM workshop 48. Altern Lab Anim 31 (4):429454.

4. Budimir N, Huckriede A, Meijerhof T, Boon L, Gostick E, Price DA, Wilschut J, de Haan A (2012) Induction of heterosubtypic cross-protection against influenza by a whole inactivated virus vaccine: the role of viral membrane fusion activity. PLoS One 7 (1):e30898. doi:10.1371/journal.pone.0030898.

5. Budowsky EI, Zalesskaya MA (1991) Principles of selective inactivation of viral genome. V. Rational selection of conditions for inactivation of the viral suspension infectivity to a given extent by the action of betapropiolactone. Vaccine 9 (5):319-325.
6. Hemminki K (1981) Reactions of beta-propiolactone, beta-butyrolactone and gamma-butyrolactone with nucleic acids. Chem Biol Interact 34 (3):323-331

7. Jagannathan S, Gandhi PR, Vijayakumar R (2013) Kinetics Analysis of Beta-propiolactone with Tangential Flow Filtration (TFF). Journal of Biological Sciences 13 (6):521-527.

8. Krebs JW, Wilson ML, Childs JE (1995) Rabies-epidemiology, prevention, and future research. Journal of Mammalogy 76 (3):681-694.

9. Lawrence SA (2000) beta-Propiolactone: viral inactivation in vaccines and plasma products. PDA J Pharm Sci Technol 54 (3):209-217.

10. Meslin F, Kaplan MM, Koprowski H, Organization WH (1996) Laboratory techniques in rabies.

11. Madhusudana SN, Shamsundar R, Seetharaman S (2004) In vitro inactivation of the rabies virus by ascorbic acid. Int J Infect Dis 8 (1):21-25. 12. Ph. Eur (2011) Influenza vaccine (whole virion, inactivated). In: Pharmacopoeia E (ed) European Pharmacopoeia, 7th ed, pp 795-798.

13. Ph. Eur (2011) Rabies vaccine for human use prepared in cell cultures In: Pharmacopoeia E (ed) European Pharmacopoeia 7th edn, pp 822-824. 14. Reed LJ, Muench H (1938) A simple method of estimating fifty per cent endpoints. American journal of epidemiology 27 (3):493-497.

15. Schuster P, Muller T, Vos A, Selhorst T, Neubert L, Pommerening E (2001) Comparative immunogenicity and efficacy studies with oral rabies virus vaccine SAD P5/88 in raccoon dogs and red foxes. Acta Vet Hung 49 (3):285-290

16. Selvaraj J, Raju MK, Rajendran V (2015) Analysis of Alternative Purification of Beta-Propiolactone Inactivated, Tangential Flow Filtration Concentrated Vero Cell Derived Rabies Vaccine. J Vaccines Vaccin 6:269. doi:10.4172/2157-7560.1000269.

17. Sureau P (1987) Rabies vaccine production in animal cell cultures. Adv Biochem Eng Biotechnol 34:111-128.

18. WHO T (2007) Recommendation for inactivated rabies vaccine for human use produced in cell substrates and embryonated eggs941. Anex, 19. Wunner WH (2007) Rabies Virus. Rabies. 2 nd ed. San Diego, CA: Elsevier Inc. 23-56. 